\title{
Completing the Continuum of Maternity Care and Associated Factors in Debre Berhan Town, Amhara, Ethiopia, 2020
}

This article was published in the following Dove Press journal: Journal of Multidisciplinary Healthcare

\author{
Michael Amera Tizazu' \\ Nigussie Tadesse Sharew (iD) ${ }^{2}$ \\ Tadesse Mamo $^{3}$ \\ Abayneh Birlie Zeru ${ }^{3}$ \\ Eyosiyas Yeshialem Asefa (D) \\ Nakachew Sewnet Amare (D) \\ 'Department of Midwifery, College of \\ Health Science, Debre Berhan University, \\ Debre Berhan, Ethiopia; ${ }^{2}$ Department of \\ Nursing, College of Health Science, \\ Debre Berhan University, Debre Berhan, \\ Ethiopia; ${ }^{3}$ Department of Public Health, \\ College of Health Science, Debre Berhan \\ University, Debre Berhan, Ethiopia
}

Correspondence: Eyosiyas Yeshialem Asefa Department of Midwifery, College of Health Science, Debre Berhan University, P. Box: 445, Debre Birhan, Ethiopia

Tel +25I-9I3836869

Email eyosil43@gmail.com
Background: The continuum of maternity care is the continuity of maternal health care services that a woman practices antenatal care, skilled birth attendant, and postnatal care. Even though there are positive inclinations towards the continuum of maternity care, the problem is still significant. So, the purpose of this study was to assess the utilization of continuum maternity care and associated factors among women who gave birth in the last 12 months before the data collection period in Debre Berhan town.

Methods: A community-based cross-sectional study was conducted from February 17 to March 15/2020. The respondents were selected by using the cluster sampling technique. Face-to-face interview was used for data collection. EpiData software version 3.1 was used for data entry and exported to SPSS version 21 for further analysis. In multivariable logistic regression, a statistically significant association has declared a p-value $<0.05$.

Results: In this study, the proportion of women who completed the continuum of maternity care was 37.2\% (95\% CI: 33.4-41.1). Completing primary education (AOR: 2.73, 95\% CI: $1.17-$ 6.38), secondary education (AOR: $3.11,95 \% \mathrm{CI}: 1.32-7.31$ ), college and above educational level (AOR: 4.15, 95\% CI: 1.79-9.57), initiation of first ANC visit $\leq 16 \mathrm{wks}$ (AOR: 2.57, 95\% CI: 1.41-4.68), knowing key pregnancy danger signs (AOR: 1.91, 95\% CI: 1.15-3.19), and well prepared on birth and complication readiness (AOR: 1.59, 95\% CI: 1.10-2.32) were found to positively increase the chance of completing maternity care in our study area.

Conclusion: Even if a higher proportion of mothers completed the continuum of maternity care in the study area than the finding at national level of 9.1\% basing EDHS 2016 data, further interventions are mandatory to reach the acceptable level. Therefore, health promotion programs targeting mothers with no education and lower educational level are important to increase their awareness about the importance of completing all levels of maternity care, health education, and counseling regarding early initiation of ANC, pregnancy danger signs, and birth preparedness and complication readiness plan.

Keywords: completion, continuum, maternity care, Ethiopia

\section{Background}

The continuum of maternity care is defined as the continuity of health care services that a woman practices Ante Natal Care (ANC), Skill Birth Attendant (SBA), and Post Natal Care (PNC). ${ }^{1}$ It is a critical strategy for reducing maternal mortality and morbidity. $^{2}$ The continuum of maternity care is an integrated service of care explained by time and space dimensions that women are required to avail of uninterruptedly. Moreover, it should be provided as a continuum throughout the 
lifecycle including adolescence, pregnancy, childbirth, and childhood; and also in seamless care that spans the home, community, and health facilities. ${ }^{3}$ Even though, there were great improvements over the last two decades, insufficient or non-existent care during pregnancy and delivery was fundamentally accountable for an estimated 295,000 maternal death in $2017 .^{2}$ In addition to saving maternal lives with CoC; Up to 160,000 newborn lives can be saved with high ANC coverage including a focused package of interventions, 390,000 additional newborn lives can be saved through high coverage of skilled childbirth care, and 310,000 lives through postnatal care. ${ }^{4}$

Globally, $86 \%$ and $65 \%$ of pregnant women accessed once and four antenatal visits respectively and treated by skilled health personnel in 2018. In Sub-Saharan Africa (52\%) and South Asia (49\%), women attended at least four antenatal visits. In Sub-Saharan Africa, not more than 57\% of mothers are delivered in a health facility. ${ }^{2}$ Each year about 18 million women in Africa gave birth at home and According to DHS data from 21 sub-Saharan African nations, only $13 \%$ of women who gave birth at home received PNC within three days. ${ }^{4}$ Different studies across the world showed a different level of continuum of care like; Nepal (41\%) remote or isolated villages or Pakistan (6.4\%) Ethiopia (9.1\%) and northwest Ethiopia (47\%). ${ }^{5-8}$

Educational status, residence, distance from the health facility, woman's decision making power, previous pregnancy-related complication, early initiation of ANC, wealth index, media access, Skills of health workers, health system supports, and presence of delivery fee was some of the identified determinant factors affecting $\mathrm{CoC}$ by different studies. ${ }^{1,4,5,8,9}$

Evidence from EDHS showed that there are improvements in the proportion of individual $\mathrm{MCH}$ care package utilizations from 2016 to 2019 in Ethiopia; where ANC increased from $62 \%$ to $74 \%$, SBA from $28 \%$ to $50 \%$, and PNC from $17 \%$ to $34 \%{ }^{10,11}$ This showed that there are large discrepancies between the utilization of ANC, SBA, and PNC services continuously. An effective continuum of care strengthens the links between the home and the first level facility and the hospital, assuring the appropriate care is available in each place. ${ }^{4}$ The maternal continuum of care can be achieved using a combination of well-defined policies and strategies to improve home care practices and health care services throughout the lifecycle, building on existing programs and packages.

Unlike other parts of the world and including Ethiopia, there is no available data or evidence regarding the proportion of mothers who completed the continuum of maternity care and factors that enhance the completion of maternity care in our study area. So this study aimed to assess the utilization of continuous maternity care and associated factors in Debre Birhan town, Ethiopia 2020.

\section{Methods}

\section{Study Design and Setting}

A cross-sectional (community-based) study was conducted from February 17 to March 15/2020 among mothers who gave birth in the last year preceding the data collection period in Debre Berhan town. Debre Berhan Town, located in the North Shewa Zone of the Amhara region, 130 kilometers far from the capital city, Addis Ababa. According to the 2019 report of Debre Berhan Town administration's mayor's office, the Town consists of nine kebeles (the smallest administrative unit) with an estimated total population of 114,652 (Male=51,843 and Female=62,809). Of the 62,809 female population, 39,066 were within the age group of 15-49 years. The town has four public (one referral hospital and three health centers) and three private health institutions. All the above health institutions had maternal health services.

\section{Sample Size and Sampling Technique}

The sample size was calculated using the single population proportion formula. The estimated proportion of completing the continuum of maternity care was taken from a related study $(48.7 \%){ }^{7}$ the confidence level of $95 \%, 5 \%$ degree of precision, design effect of 1.5 , and non-response rate of $10 \%$, was assumed. The final sample size was estimated to be 634 mothers.

Study participants were selected using a cluster sampling technique. From the total of 9 kebeles in the town, 5 kebeles were selected by the lottery method, and all mothers in the selected kebeles who fulfill the eligibility criteria were incorporated in the study. We found a total of 659 women who full fill the inclusion criteria from the selected clusters using data from health extension workers (registration log book) and all of them were included in to our study.

\section{Population}

Mothers who gave their most recent birth in the last 12 months, who had booked for ANC, and those who were at six weeks or more after birth at the time of data collection were included. Women who lived in the study area for less 
than six months at the period of data collection were excluded from the study.

\section{Data Collection Tools and Procedures}

Data were collected through face to face interviews using pre-tested structured questionnaires by trained data collectors. The data collection tool was adapted from the Ethiopian Demographic and Health Survey (EDHS) and other literature. $^{7,10,12-17}$ The tool incorporates socio-demographic, reproductive and obstetrics, and maternal health service-related variables.

\section{Measurement}

- Completing the continuum of maternity care: was considered if the women had four or more ANC visits and childbirth and at least one PNC after discharge from the health facilities within six weeks by skilled health personnel (medical doctors, midwives, nurses, health officers, or community health extension workers) or with in the first week by community health extension workers during their home visit. If they missed any one of the above visits, it is considered an incomplete continuum of maternity care. ${ }^{14}$

- Knowledgable about pregnancy danger signs: women were categorized as knowledgeable if they stated at least two of the four key pregnancy danger signs (vaginal bleeding, severe headache, blurring of vision, and swelling of the face); if not they were categorized as not knowledgeable. ${ }^{14}$

- Not Knowledgable about pregnancy danger signs: women were categorized as not knowing if they stated at less than two of the four key pregnancy danger signs (vaginal bleeding, severe headache, blurring of vision, and swelling of the face); if not they were categorized as not knowledgeable. ${ }^{14}$

- Well prepared for birth preparedness and complication readiness were considered when women reported that they have applied five or more of (BPCR) otherwise considered as "not well prepared". The elements of BPCR considered in this study were identified birthplace, recognized sign of labor, identify supplies needed during labor/delivery, saving money for an emergency, identified emergency transportation, people to support during/after birth, and identified potential blood donors as needed. ${ }^{18,19}$

- Planned pregnancy: A woman who plans to become pregnant by making lifestyle choices for optimal health in advance of the planned conception.
- Unplanned pregnancy: happened mainly due to the results of not using contraception or inconsistent or incorrect use of effective methods.

- Health extension workers: Health Extension Workers are short term trained health workers assigned to local health posts and provide a package of essential interventions to meet population health needs at this level.

\section{Data Quality Assurance}

Five data collectors (two Midwives and three Nurses) and two supervisions were recruited to collect the data of the study. One-day training on the objective of the study, sampling technique, and data collection tool was provided. Back and forth questionnaire translation was done to check its consistency with the original meaning. Before commencing data collection, a pre-test was conducted among 5\% of the study sample and, the required adjustments were made on unclear questions.

\section{Data Processing and Analysis}

Data were coded and entered after checking the completeness of the data. EpiData software version 3.1 was used for data entry and SPSS version 21 was used for analysis. Descriptive statistics were used to measure the proportion of women who complete the continuum of maternity care and other variables of the study participants. Variables with a $\mathrm{P}$ value of less than 0.25 on bivariate logistic regression were selected as a candidate for multivariate logistic regression. Finally, multivariable Logistic regressions were used to assess the relative impact of explanatory variables on dependent variables and to select important predictors of the continuum of maternity care. Hosmer and Lemeshow goodness of test was used to check Model fitness and variance inflation factor was applied to diagnosed multicollinearity between the explanatory variables with cut-off point VIF $>10$ as problematic. $^{20}$ In multivariable logistic regression, a statistically significant association was declared a p-value less than 0.05 to determine factors associated with the completion of the continuum of maternity- care and reported by using adjusted odds ratio with $95 \% \mathrm{CI}$.

\section{Ethical Consideration}

A letter of Ethical clearance was secured from the Institutional Review Board (IRB) of health Science College, Debre Berhan University. A formal letter of permission was obtained from the Debre Berhan town health 
office. Informed written consent was obtained from study subjects. Additionally, after doing the witness attests that the consent information was accurately explained for those who cannot read and write, that the subject apparently understood the information, and informed consent was given freely. Participants had the right to self-determination regarding participation in research, both initially and during the research. For confidentiality purposes, the names of the participant were not included in the questionnaire. The collected data were kept confidential and used only for the study. This study was conducted following the Declaration of Helsinki.

\section{Results}

\section{Socio-Demographic Characteristics}

A total of 647 women were interviewed, giving a response rate of $98.2 \%$. The majority $442(68.3 \%)$ of respondents were aged 25-34 years and the mean age was $28.5 \pm 4.48$ years. Most women 605 (93.5\%), were married and 28 (4.3\%) were divorced. While 67 (10.4\%) did not attend modern education, $259(40.0 \%)$ had college and above education. Nearly $96 \%$ were Amhara in ethnicity. Five hundred seventy-one (88.2\%) were Orthodox Christians. Most 591 (91.3\%) had information about maternal health services. Almost half 339 (52.4\%) of participant's partners achieved tertiary education, and $260(40.2 \%)$ of them were government employees (see Table 1).

\section{Reproductive Health and Maternal Health Service-Related Characteristics}

Among study participants, 247 (38.2\%) of women were in the first pregnancy, whereas $64(9.9 \%)$ had four and more pregnancies. Six hundred twenty-six (96.8\%) of the participant's recent pregnancy was planned. Five hundred twenty-nine $(81.8 \%)$ of women had initiated their first antenatal visit at $\leq 16$ weeks of gestation and 482 (74.5\%) had four or more antenatal care visits throughout their pregnancy (see Table 2).

Out of all respondents, 412 (63.7\%) of women received their antenatal care at public health centers. Five hundred twenty-two $(80.7 \%)$ got husband's support during maternal health visit. Regarding the services taken during the pregnancy period; 635 (98.1\%) measured their blood pressure, and 609 (94.1\%) received nutritional counseling (see Figure 1).

Almost all respondents, 641 (99.1\%) had skilled birth attendant/health facility delivery, of which 210 (32.8\%) had stayed in the health facility for $24 \mathrm{hrs}$ or more after delivery and 324 (50.5\%) had informed on when to return for PNC (see Table 3).

\section{The Proportion of Women Completing the Continuum of Maternity Care}

The overall proportion of women completing the continuum of maternity care was $37.2 \%$ (95\%, CI: $33.4-41.1$ ). Additionally, 482 (74.5\%) mothers had at least four ANC visits, and $480(74.2 \%)$ of them delivered at a health facility by skilled birth attendants. Correspondingly, from those who had ANC4+ and SBA, 241 (37.2\%) got at least one PNC within six weeks of discharge (see Figure 2).

\section{Factors Associated with Completing the Continuum of Maternity Care}

The current study has identified some important factors that are associated with the completion of the continuum of maternity care in Debre Berhan town. Maternal educational status, initiation of ANC visit $\leq 16$ wks of gestation, knowing pregnancy key danger signs, and well prepared on birth and complication readiness plan become a statistically significant association with the outcome variable.

The odds of completing the continuum of maternity care was higher among educated women; women who attend primary education (AOR: 2.73 , 95\% CI: $1.17-$ 6.38), secondary education (AOR: $3.11,95 \%$ CI: $1.32-$ 7.31), and college and above (AOR: $4.15,95 \%$ CI: 1.79 9.57) contribute for completing the continuum of maternity care than those who had no education. The odds of completing the continuum of maternity care was almost three times higher for those who had their first ANC visit at $\leq 16$ weeks of gestation than their counterparts (AOR: 2.57, 95\% CI: $1.41-4.68$ ). Similarly, the odds of completing the continuum of maternity care were $91 \%$ higher among women knowledgeable on the key danger signs of pregnancy than those who were not knowledgeable (AOR: 1.91, 95\% CI: 1.15-3.19). Women who were well prepared on birth preparedness and complication readiness plan had higher odds to accomplish continuum of maternity care than those who had not (AOR: $1.59,95 \%$ CI: 1.10-2.32) (see Table 4).

\section{Discussion}

The finding of this study showed that about one-third (37.2\%, 95\% CI: 33.4-41.1) of women in the study area received all elements of the continuum of maternity care. 
Table I Socio-Demographic Characteristics of Study Participants in Debre Berhan Town, North Shewa, Amhara, Ethiopia 2020 $(n=647)$

\begin{tabular}{|c|c|c|c|}
\hline \multicolumn{2}{|l|}{ Characteristics } & \multirow{4}{*}{$\begin{array}{l}\text { Frequency } \\
124 \\
442 \\
81\end{array}$} & \multirow{4}{*}{$\begin{array}{l}\text { Percentage (\%) } \\
19.2 \\
68.3 \\
12.5\end{array}$} \\
\hline Age of women in years & $19-24$ & & \\
\hline & $25-34$ & & \\
\hline & $\geq 35$ & & \\
\hline \multirow[t]{4}{*}{ Religion } & Orthodox & 571 & 88.2 \\
\hline & Muslim & 36 & 5.6 \\
\hline & Protestant & 35 & 5.4 \\
\hline & Others & 5 & 0.8 \\
\hline \multirow[t]{2}{*}{ Ethnicity } & Amhara & 620 & 95.8 \\
\hline & Others (Oromo, Tigre ...) & 27 & 4.2 \\
\hline \multirow[t]{4}{*}{ Marital status } & Married & 605 & 93.5 \\
\hline & Divorced/separated & 28 & 4.3 \\
\hline & Widowed & 5 & 0.8 \\
\hline & Single & 9 & 1.4 \\
\hline \multirow[t]{4}{*}{ Educational status } & No education & 67 & 10.4 \\
\hline & Primary education $(\mathrm{I}-8)$ & 183 & 28.3 \\
\hline & Secondary education(9-12) & 138 & 21.3 \\
\hline & College and above & 259 & 40.0 \\
\hline \multirow[t]{6}{*}{ Occupation } & Farmer & 15 & 2.3 \\
\hline & Housewife & 312 & 48.2 \\
\hline & Private employed & 73 & 11.3 \\
\hline & Gov't employed & 170 & 26.3 \\
\hline & Merchant & 48 & 7.4 \\
\hline & Others & 29 & 4.5 \\
\hline \multirow[t]{4}{*}{ Family monthly income(ETB) } & $\leq 500$ & 8 & 1.2 \\
\hline & $501-1500$ & 52 & 8.1 \\
\hline & $|50|-2500$ & 94 & 14.5 \\
\hline & $\geq 250$ I & 493 & 76.2 \\
\hline \multirow[t]{4}{*}{ Educational status of partner } & No education & 51 & 7.9 \\
\hline & Primary education $(I-8)$ & 101 & 15.6 \\
\hline & Secondary education(9-12) & 156 & 24.1 \\
\hline & College and above & 339 & 52.4 \\
\hline \multirow[t]{6}{*}{ Occupation of partner } & Farmer & 36 & 5.6 \\
\hline & Private employed & 145 & 22.4 \\
\hline & Gov't employed & 260 & 40.2 \\
\hline & Merchant & 144 & 22.3 \\
\hline & Daily laborer & 39 & 6.0 \\
\hline & Others & 23 & 3.5 \\
\hline \multirow[t]{2}{*}{ Ever Heard maternal health services } & Yes & 591 & 91.3 \\
\hline & No & 56 & 8.7 \\
\hline \multirow[t]{3}{*}{ Source of maternal health information $(n=591)$} & Mass-media(tv/radio) & 207 & 35.0 \\
\hline & Health care provider & 362 & 61.3 \\
\hline & Others & 22 & 3.7 \\
\hline
\end{tabular}


Table 2 Reproductive and Obstetrics Characteristics of Study Participants in Debre Berhan Town, North Shewa, Amhara, Ethiopia, $2020(n=647)$

\begin{tabular}{|c|c|c|c|}
\hline \multicolumn{2}{|l|}{ Characteristics } & \multirow{4}{*}{$\begin{array}{l}\text { Frequency } \\
247 \\
336 \\
64\end{array}$} & \multirow{4}{*}{$\begin{array}{l}\text { Percentage (\%) } \\
38.2 \\
51.9 \\
9.9\end{array}$} \\
\hline Number of pregnancy & 1 & & \\
\hline & $2-3$ & & \\
\hline & $\geq 4$ & & \\
\hline \multirow[t]{2}{*}{ Pregnancy planned } & Yes & 626 & 96.8 \\
\hline & No & 21 & 3.2 \\
\hline \multirow[t]{3}{*}{ Number of children } & 1 & 253 & 39.1 \\
\hline & $2-3$ & 339 & 52.4 \\
\hline & $\geq 4$ & 55 & 8.5 \\
\hline \multirow[t]{2}{*}{ Number of ANC visit for the last pregnancy } & $<4$ & 165 & 25.5 \\
\hline & $\geq 4$ & 482 & 74.5 \\
\hline \multirow[t]{2}{*}{ Timing of first ANC visit for the last pregnancy } & $\leq 16$ weeks & 529 & 81.8 \\
\hline & $>16$ weeks & 118 & 18.2 \\
\hline
\end{tabular}

This finding was consistent with the study done in Nepal where $41 \%$ of the women received Antenatal Care (ANC), delivery from Skilled Birth Attendant (SBA) as well as the Postnatal Care (PNC) during their most recent birth. $^{5}$

This finding was higher than the study conducted in two studies from Ethiopia (9.1\%), ${ }^{7}$ Arbaminch Zuria woreda $9.7 \%{ }^{21}$ Ghana $(8 \%),{ }^{17}$ Tanzania $(10 \%),{ }^{14}$ remote or isolated villages of Pakistan $(6.4 \%)^{6}$ and trend study in Pakistan $(27 \%),{ }^{13}$ This difference might be due to, our study was conducted only in urban areas while the compared studies were done at a general level and specifically at rural areas which had relatively creates a better chance of accessing maternal health services. This was supported by studies showing that being rural resident negatively affect the chance of receiving full continuum of maternal care than urbans. ${ }^{8,9,22}$

On the other hand; the finding of this study was found to be lower than the evidence from study done in northwest Ethiopia 47\% (CI (43.2\%-50.2\%)), ${ }^{8}$ Debre Markos town (67.8\%), ${ }^{23} \mathrm{Nepal}(45.7 \%),{ }^{24}$ Cambodia $(60 \%),{ }^{16}$ and Egypt (50.4\%). ${ }^{12}$ This variation could be explained by the

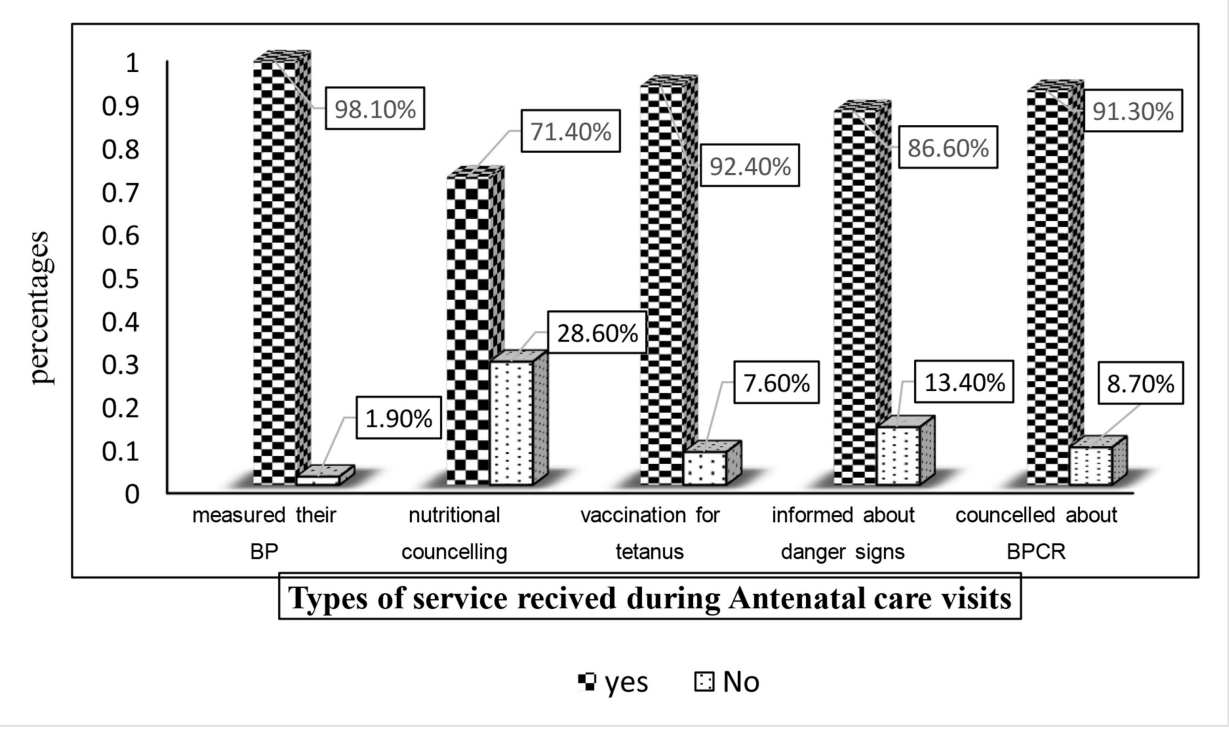

Figure I Types of health services received during antenatal care visits in Debre Berhan Town, Ethiopia 2020. 
Table 3 Maternal Health Service-Related Characteristics of Study Participants in Debre Berhan Town, North Shewa, Amhara, Ethiopia, $2020(n=647)$

\begin{tabular}{|c|c|c|c|}
\hline \multicolumn{2}{|l|}{ Characteristics } & \multirow{5}{*}{$\begin{array}{l}\text { Frequency } \\
149 \\
412 \\
46 \\
40\end{array}$} & \multirow{5}{*}{$\begin{array}{l}\text { Percentage (\%) } \\
23.0 \\
63.7 \\
7.1 \\
6.2\end{array}$} \\
\hline Place of ANC visit & Gov't hospital & & \\
\hline & Gov't health center & & \\
\hline & Private hospital & & \\
\hline & Private clinic & & \\
\hline \multirow[t]{2}{*}{ Partner support } & Yes & 522 & 80.7 \\
\hline & No & 125 & 19.3 \\
\hline \multirow[t]{2}{*}{ Informed pregnancy danger sign } & Yes & 598 & 92.4 \\
\hline & No & 49 & 7.6 \\
\hline \multirow[t]{2}{*}{ Knowledge on danger sign $(n=598)$} & Knowledgeable & 502 & 83.9 \\
\hline & Not knowledgeable & 96 & 16.1 \\
\hline \multirow[t]{2}{*}{ Blood pressure measured at ANC } & Yes & 635 & 98.1 \\
\hline & No & 12 & 1.9 \\
\hline \multirow[t]{2}{*}{ Urine sample taken } & Yes & 623 & 96.3 \\
\hline & No & 24 & 3.7 \\
\hline \multirow[t]{2}{*}{ Blood sample taken } & Yes & 638 & 98.6 \\
\hline & No & 9 & 1.4 \\
\hline \multirow[t]{2}{*}{ Nutritional counseling } & Yes & 609 & 94.1 \\
\hline & No & 38 & 5.9 \\
\hline \multirow[t]{2}{*}{ TT vaccine at ANC } & Yes & 462 & 71.4 \\
\hline & No & 185 & 28.6 \\
\hline \multirow[t]{2}{*}{ Number of TT vaccine $(n=462)$} & One & 129 & 27.9 \\
\hline & Two or more & 333 & 72.1 \\
\hline \multirow[t]{2}{*}{ Iron tablet taken } & Yes & 591 & 91.3 \\
\hline & No & 56 & 8.7 \\
\hline \multirow[t]{2}{*}{ Deworming during ANC } & Yes & 250 & 38.6 \\
\hline & No & 397 & 61.4 \\
\hline \multirow[t]{2}{*}{ Informed about Birth preparedness plan } & Yes & 560 & 86.6 \\
\hline & No & 87 & 13.4 \\
\hline \multirow[t]{2}{*}{ Status of Birth preparedness $(n=560)$} & Well prepared & 297 & 53.0 \\
\hline & Not well prepared & 263 & 47.0 \\
\hline \multirow[t]{2}{*}{ Place of birth } & Home & 6 & 0.9 \\
\hline & Health facility & 641 & 99.1 \\
\hline \multirow[t]{4}{*}{ Type of facility $(n=64 I)$} & Gov't hospital & 340 & 53.0 \\
\hline & Gov't health center & 275 & 42.9 \\
\hline & Private hospital & 24 & 3.7 \\
\hline & Private clinic & 2 & 0.3 \\
\hline \multirow[t]{2}{*}{ Duration of stay after birth $(n=64 I)$} & $<24$ hours & 431 & 67.2 \\
\hline & $\geq 24$ hours & 210 & 32.8 \\
\hline \multirow[t]{2}{*}{ Informed danger sign at $\mathrm{PNC}(\mathrm{n}=64 \mathrm{I})$} & Yes & 547 & 85.3 \\
\hline & No & 94 & 14.7 \\
\hline
\end{tabular}

(Continued) 
Table 3 (Continued).

\begin{tabular}{|c|c|c|c|}
\hline \multicolumn{2}{|l|}{ Characteristics } & \multirow{3}{*}{$\begin{array}{l}\text { Frequency } \\
500 \\
47\end{array}$} & \multirow{3}{*}{$\begin{array}{l}\text { Percentage (\%) } \\
91.4 \\
8.6\end{array}$} \\
\hline Knowledge on $\mathrm{PNC}(\mathrm{n}=547)$ & Knowledgeable & & \\
\hline & Not knowledgeable & & \\
\hline \multirow[t]{2}{*}{ Informed when to return for $\mathrm{PNC}(\mathrm{n}=64 \mathrm{I})$} & Yes & 324 & 50.5 \\
\hline & No & 317 & 49.5 \\
\hline \multirow[t]{2}{*}{ Post natal visit after discharge $(n=64 I)$} & Yes & 323 & 50.4 \\
\hline & No & 318 & 49.6 \\
\hline \multirow[t]{4}{*}{ Timing of first PNC after delivery $(n=327)$} & First day(24hrs) & 20 & 6.1 \\
\hline & Day 3(48-72hrs) & 71 & 21.7 \\
\hline & Between days 7-14 & 142 & 43.4 \\
\hline & Six weeks & 94 & 28.7 \\
\hline \multirow[t]{3}{*}{ Number of $\mathrm{PNC}(\mathrm{n}=327)$} & One & 169 & 51.7 \\
\hline & Two & 121 & 37.0 \\
\hline & Three or more & 37 & 11.3 \\
\hline \multirow[t]{5}{*}{ Place of $P N C$ received $(n=327)$} & Gov't hospital & 86 & 26.3 \\
\hline & Gov't health center & 223 & 68.2 \\
\hline & Private hospital & 10 & 3.1 \\
\hline & Private clinic & 6 & 1.8 \\
\hline & Others & 2 & 0.6 \\
\hline
\end{tabular}

difference in study settings like study period, sample size, and study area in addition to the possible difference in socio-demographic characteristics.

Women's educational status was positively associated with completing the continuum of maternity care. Women with primary education, secondary education, and college or above education had nearly three and higher odds of completing the continuum of maternity care compared to

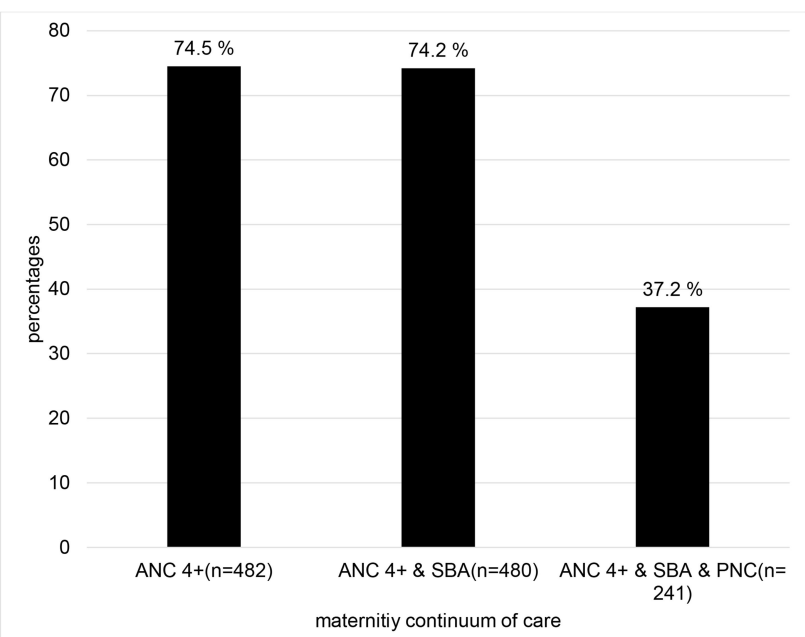

Figure 2 Proportion of women completing the maternity continuum of care along the continuum care path way in Debre Berhan Town, Ethiopia 2020. non-educated women. This is consistent with studies in Northwest Ethiopia, Nepal, and Pakistan. ${ }^{8,13,24}$ The above finding is also maintained by other studies in which, maternal educational status of secondary school and above were positively associated with maternal health service utilization. ${ }^{15,25}$ Increasing women's education alters the traditional balance of power within the family, leading to changes in decision making and allocation of resources within the households, modifies women's beliefs about disease causation and cure, influencing domestic child care practices, use of modern health care services, improving their ability to communicate with health care providers, increase antenatal healthcare use, potentially owing to changes in women's cognitive skills, economic resources, and autonomy. ${ }^{7,26,27}$

Early initiation of antenatal care increases the odds of completing the continuum of maternity care. The odds of completing the continuum of maternity care was almost 3 times higher for those who had their first ANC visit at $\leq 16$ weeks of gestation than their counterparts. This finding was supported by a study done in northwest Ethiopia where early initiation of ANC visits was significantly associated with the completion of maternity care. ${ }^{8}$ This could be explained by, women who are late for booking of ANC will have a poor birth preparedness plan, lower 
Table 4 Bivariable and Multivariable Logistic Regression Analysis of Factors Associated with the Completion of Maternity Continuum of Care in Debre Berhan Town, North Shewa, Amhara, Ethiopia, 2020 ( $n=647)$

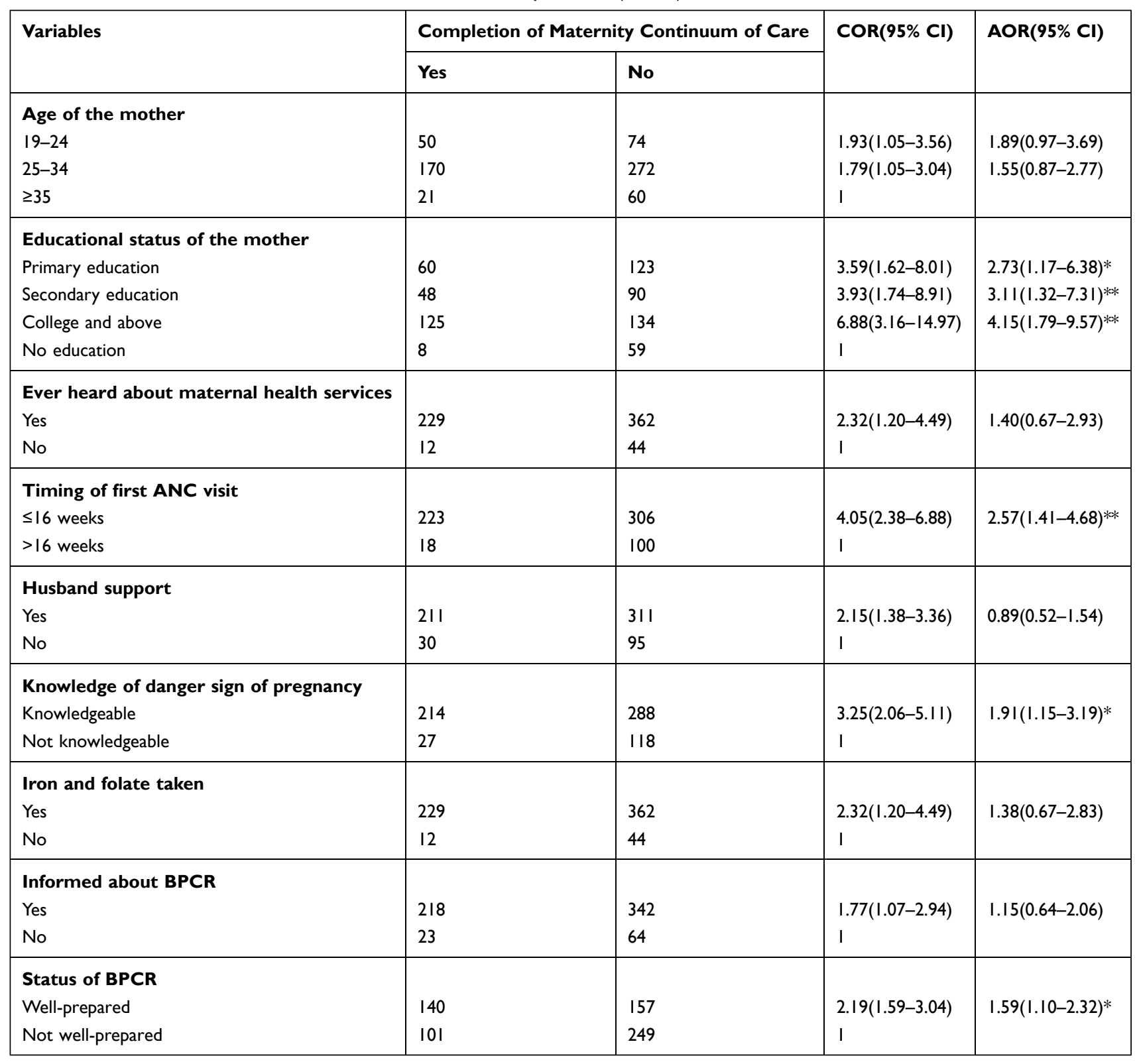

Notes: ${ }^{*} p<0.05$, ${ }^{*} p<0.01$.

Abbreviations: I, reference, BPCR, birth preparedness and complication readiness; COR, crude odds ratio; AOR, adjusted odds ratio.

knowledge of the expected date of delivery, lower likelihood of having a birth plan in terms of the desired place of delivery, preferred birth attendant, birth companion, means of transport and blood donor. Additionally early booking of ANC was found to increase emergency preparedness with better knowledge of danger signs during pregnancy and postpartum periods. ${ }^{28}$ Additionally, this might be early ANC booking creates great opportunity to familiarize themselves with the health facility environment and this, in turn, would have helped them to avoid needless fear and stress related to maternal health service use. It also helps women to set birth plans by discussing with the ANC provider and hence increase women's occurrence to complete the continuum of maternity care. $^{29,30}$

The odds of completing the continuum of maternity care were almost 2 times higher among those women who were knowledgeable about the danger signs of pregnancy than their counterparts. This finding is in agreement with the prior studies conducted in Ethiopia. ${ }^{7,22}$ Another study 
done in rural Haramaya District, Eastern Ethiopia revealed that women with knowledge of pregnancy complications were more likely to seek maternal health service utilization as compared with their counterparts. ${ }^{31}$ The reason might be knowledgeable women have understandings of the consequences of pregnancy danger signs and its complications. This increases their curiosity and accountability for their own and their child's health.

This study also revealed that the BPCR status of women ahead of childbirth is an important predictor of completing the continuum of maternity care. Those women who were well prepared on birth preparedness and complication readiness plan had $60 \%$ more likely to complete the continuum of maternity care than those who were not well prepared. This finding is supported by studies conducted in Goba district and Nepal respectively.18,19 This might be due to well-prepared women have recognized the value of birth preparedness and complication readiness plan, and better social support to get maternal health services. This helped women to increase the use of skilled care at birth and to increase the timely use of facility care for obstetric and newborn complications. ${ }^{32}$

\section{Limitation of the Study}

The finding of this study might not be representative of the zonal population since it was done in an urban area. Additionally, there might be recall bias during our data collection, but we tried to manage it by including data regarding their recent births.

\section{Conclusion and Recommendations}

The proportion of women completing the continuum of maternity care was low in Debre Berhan town according to the expected proportion according to the world health organization and ministry of health recommendations. So Health promotion programs targeting mothers with no education and lower educational level are important to increase their awareness about the importance of completing all levels of maternity care. Additionally, health facilities should intensively work on increasing the early initiation of ANC using different methods of information dissemination, counseling, and health education. Finally, increasing women's knowledge about pregnancy danger signs through counseling and health education, as well as encouraging them to be well prepared for birth and ready for possible complications are important to improve maternal use of a continuum of care. Finally, we recommend further researches to be done addressing both urban and rural areas supplemented with qualitative data.

\section{Abbreviations}

ANC, antenatal care; AOR, adjusted odds ratio; BPCR, birth preparedness and complication readiness; CI, confidence interval; $\mathrm{CoC}$, continuum of care; $\mathrm{COR}$, crude odds ratio; EDHS, Ethiopian Demographic and Health Survey; EMDHS, Ethiopian Mini Demographic and Health Survey; HSTP, Health Sector Transformation Plan; MMR, maternal mortality ratio; PNC, postnatal care; SBA, skill birth attendant; WHO, World Health Organization.

\section{Data Sharing Statement}

The datasets used and/or analyzed during the current study are available from the corresponding author on reasonable request.

\section{Acknowledgment}

We would like to thank Debre Berhan University, College of health science, department of public health, participants, data collectors, and supervisors, to our friends and colleagues for their valuable support throughout the research process.

\section{Author Contributions}

All authors contributed to data analysis, drafting or revising the article, have agreed on the journal to which the article will be submitted, gave final approval of the version to be published, and agree to be accountable for all aspects of the work.

\section{Funding}

The required total financial cost to do this research was covered by Debre Berhan University, Ethiopia but it has no role in the publication.

\section{Disclosure}

The authors declare that they have no conflicts of interest for this work.

\section{References}

1. Owili PO, Muga MA, Mendez BR, et al. Quality of maternity care and its determinants along the continuum in Kenya: a structural equation modeling analysis. PLoS One. 2017;12(5):e0177756. doi:10.1371/ journal.pone. 0177756

2. UNICEF. Antenatal care, based on population based national household survey data and routine health systems. 2019. 
3. Lawn J, Kerber K, Opportunities for Africa's newborns: practical data, policy and programmatic support for newborn care in Africa. Partnership for Maternal, Newborn and Child Health, Cape Town, 2006. 32.

4. Kerber KJ, de Graft-Johnson JE, Bhutta ZA, Okong P, Starrs A, Lawn JE. Continuum of care for maternal, newborn, and child health: from slogan to service delivery. The Lancet. 2007 Oct 13;370 (9595):1358-69.

5. Chalise B, Chalise M, Bista B, et al. Correlates of continuum of maternal health services among Nepalese women: evidence from Nepal Multiple Indicator Cluster Survey. PLoS One. 2019;14(4): e0215613. doi:10.1371/journal.pone.0215613

6. Maheen H, Hoban E, Bennett C. Factors affecting rural women's utilisation of continuum of care services in remote or isolated villages or Pakistan-a mixed-methods study. Women Birth. 2020 doi:10.1016/j.wombi.2020.04.001

7. Chaka EE, Parsaeian M, Majdzadeh R. Factors associated with the completion of the continuum of care for maternal, newborn, and child health services in Ethiopia. Multilevel model analysis. Int J Prev Med. 2019;10.

8. Asratie MH, Muche AA, Geremew AB, Amo-Adjei J. Completion of maternity continuum of care among women in the post-partum period: magnitude and associated factors in the northwest, Ethiopia. PLoS One. 2020;15(8):e0237980. doi:10.1371/journal.pone.0237980

9. Akinyemi JO, Afolabi RF, Awolude OA. Patterns and determinants of dropout from maternity care continuum in Nigeria. BMC Pregnancy Childbirth. 2016;16(1):282. doi:10.1186/s12884-016-1083-9

10. CSACE, I. Ethiopia Demographic and Health Survey 2016. Addis Ababa, Ethiopia, and Rockville, Maryland, USA: CSA and ICF; 2016.

11. Institute, E.P.H. and ICF. Ethiopia Mini Demographic and Health Survey 2019: Key Indicators. Rockville, Maryland, USA: EPHI and ICF; 2019.

12. Hamed A, Mohamed E, Sabry M. Egyptian status of continuum of care for maternal, newborn, and child health: Sohag Governorate as an example. Int J Med Sci Public Health. 2018;7(6):1. doi:10.5455/ ijmsph.2018.0102607032018

13. Iqbal S, Maqsood S, Zakar R, et al. Continuum of care in maternal, newborn and child health in Pakistan: analysis of trends and determinants from 2006 to 2012. BMC Health Serv Res. 2017;17(1):189. doi:10.1186/s12913-017-2111-9

14. Mohan D, LeFevre AE, George A, et al. Analysis of dropout across the continuum of maternal health care in Tanzania: findings from a cross-sectional household survey. Health Policy Plan. 2017;32 (6):791-799. doi:10.1093/heapol/czx005

15. Shibanuma A, Yeji F, Okawa S, et al. The coverage of continuum of care in maternal, newborn and child health: a cross-sectional study of woman-child pairs in Ghana. BMJ Glob Health. 2018;3(4):e000786. doi:10.1136/bmjgh-2018-000786

16. Wang W, Hong R. Levels and determinants of continuum of care for maternal and newborn health in Cambodia-evidence from a population-based survey. BMC Pregnancy Childbirth. 2015;15(1):62. doi:10.1186/s12884-015-0497-0

17. Yeji F, Shibanuma A, Oduro A, et al. Continuum of care in a maternal, newborn and child health program in Ghana: low completion rate and multiple obstacle factors. PLoS One. 2015;10(12): e0142849. doi:10.1371/journal.pone.0142849
18. Belda SS, Gebremariam MB. Birth preparedness, complication readiness and other determinants of place of delivery among mothers in Goba District, Bale Zone, South East Ethiopia. BMC Pregnancy Childbirth. 2016;16(1):73. doi:10.1186/s12884-016-0837-8

19. Nawal D, Goli S, Baradaran HR. Birth preparedness and its effect on place of delivery and post-natal check-ups in Nepal. PLoS One. 2013;8(5):e60957. doi:10.1371/journal.pone.0060957

20. Vittinghoff E, Glidden DV, Shiboski SC, McCulloch CE. Regression Methods in Biostatistics: Linear, Logistic, Survival, and Repeated Measures Models. Springer Science \& Business Media; 2011.

21. Haile D, Kondale M, Andarge E, et al. Level of completion along continuum of care for maternal and newborn health services and factors associated with it among women in Arba Minch Zuria woreda, Gamo zone, Southern Ethiopia: a community based cross-sectional study. PLoS One. 2020;15(6):e221670. doi:10.1371/journal.pone.0221670

22. Muluneh AG, Kassa GM, Alemayehu GA, et al. High dropout rate from maternity continuum of care after antenatal care booking and its associated factors among reproductive age women in Ethiopia, Evidence from Demographic and Health Survey 2016. PLoS One. 2020;15(6):e0234741. doi:10.1371/journal.pone.0234741

23. Amare NS, Araya BM, Asaye MM. Dropout from maternity continuum of care and associated factors among women in Debre Markos town, Northwest Ethiopia. bioRxiv. 2019;620120.

24. Tamang TM Factors associated with completion of continuum of Care for Maternal Health in Nepal. in proceedings of the IUSSP XXVIII International Population Conference, Cape Town, South Africa. 2017.

25. Fekadu GA, Ambaw F, Kidanie SA. Facility delivery and postnatal care services use among mothers who attended four or more antenatal care visits in Ethiopia: further analysis of the 2016 demographic and health survey. BMC Pregnancy Childbirth. 2019;19(1):64. doi:10.1186/s12884-019-2216-8

26. Weitzman A. The effects of women's education on maternal health: evidence from Peru. Soc Sci Med. 2017;180:1-9. doi:10.1016/j. socscimed.2017.03.004

27. Elo IT. Utilization of maternal health-care services in Peru: the role of women's education. Health Transition Rev. 1992;2:49-69.

28. Atisa FO. Influence of Early Booking for Antenatal Care on Antenatal and Early Pregnancy Outcomes at Kenyatta National Hospital. University of Nairobi; 2015.

29. Bishanga DR, Drake M, Kim Y-M, et al. Factors associated with institutional delivery: findings from a cross-sectional study in Mara and Kagera regions in Tanzania. PLoS One. 2018;13(12):e0209672. doi:10.1371/journal.pone.0209672

30. Tiruneh GT, Worku A, Berhane Y, et al. Determinants of postnatal care utilization in Ethiopia: a multilevel analysis. BMC Pregnancy Childbirth. 2020;20(1):1-12. doi:10.1186/s12884-020-03254-7

31. Kifle D, Azale T, Gelaw YA, et al. Maternal health care service seeking behaviors and associated factors among women in rural Haramaya District, Eastern Ethiopia: a triangulated communitybased cross-sectional study. Reprod Health. 2017;14(1):6. doi:10.1186/s12978-016-0270-5

32. WHO. WHO recommendation on birth preparedness and complication readiness 31 May 2015.2015 


\section{Publish your work in this journal}

The Journal of Multidisciplinary Healthcare is an international, peerreviewed open-access journal that aims to represent and publish research in healthcare areas delivered by practitioners of different disciplines. This includes studies and reviews conducted by multidisciplinary teams as well as research which evaluates the results or conduct of such teams or healthcare processes in general. The journal covers a very wide range of areas and welcomes submissions from practitioners at all levels, from all over the world. The manuscript management system is completely online and includes a very quick and fair peer-review system. Visit http://www.dovepress.com/testimonials. php to read real quotes from published authors. 